Article

\title{
Free-Radical Bulk-Photopolymerization Process as a Method of Obtaining Thermally Curable Structural Self-Adhesive Tapes and Effect of Used Type I Photoinitiators
}

\author{
Konrad Gziut ${ }^{\circledR}$, Agnieszka Kowalczyk *(D) and Beata Schmidt $(\mathbb{C}$ \\ Department of Chemical Organic Technology and Polymeric Materials, Faculty of Chemical Technology and \\ Engineering, West Pomeranian University of Technology in Szczecin, 70-322 Szczecin, Poland; \\ konrad.gziut@zut.edu.pl (K.G.); beata.schmidt@zut.edu.pl (B.S.) \\ * Correspondence: agnieszka.kowalczyk@zut.edu.pl
}

Received: 27 August 2020; Accepted: 23 September 2020; Published: 24 September 2020

\begin{abstract}
A new fabrication method for thin $(120 \mu \mathrm{m})$ thermally curable structural self-adhesive tapes (SATs) was demonstrated by utilizing a series of acrylic syrups (ASs) modified using Bisphenol A-based liquid epoxy resin. The acrylic syrups containing poly(butyl acrylate-co-butyl methacrylate-co-glycidyl methacrylate-co-2-hydroxyetyl acrylate-co-4-acryloyloxy benzophenone) were synthesized via free-radical bulk-photopolymerization (FRBP) process. Influence of different type I radical photoinitiators (PIs), i.e., $\alpha$-hydroxyalkylphenones (HPs), acylphosphine oxides (APOs) and its mixtures (HPs/APOs and APO/APO) on selected physico-chemical features of obtained ASs was studied. It turned out that APO-type PIs are more effective in the FRBP process (NMR studies). Self-adhesive tests of SATs revealed that the monomers' conversion in ASs have a significant influence on adhesion and tack. Moreover, the polymer structures formed at the UV cross-linking stage of SATs significantly affect the cross-linking degree of SATs during thermal curing (differential scanning calorimetry method). The highest values of overlap shear strength were achieved by SATs based on ASs with monomers' conversion on the level 50-60\%.
\end{abstract}

Keywords: polymer synthesis; bulk photopolymerization; photoinitiators; acrylate syrup; structural adhesives; adhesion

\section{Introduction}

Structural adhesives in the form of thin films are widely used in automotive and aircraft construction for the fabrication of honeycomb structures because of their form (i.e., thin film), lower joint weight, and uniform distribution of stresses along the joint [1-4]. The most common type of such adhesives is those intended for thermal curing (i.e., thermally curable structural adhesive in the form of a solid tape). The first structural adhesive tape (SAT) was manufactured by Hexcel from phenolic resin and a polyvinyl formal. Nowadays, several SATs based on different phenolic and epoxy resins are produced [5]. Literature related to the fabrication of adhesive films is limited and the clear information is rather intellectually protected. There are only very few data about structural adhesive films' preparation or modification. The latest revealed a moisture effect on commercial structural adhesive film [6], using epoxy resins modified with oxazolidinone [7] or polysulfones [8]. A particular kind of the SATs is those with self-adhesive features. They can be prepared, for example, via a UV-photo cross-linking process of reactive acrylate copolymers (obtained in classical free-radical copolymerization process initiated by $2,2^{\prime}$-azobis(isobutyronitryle) and in the presence of organic solvent) compounded with epoxy resin and latent curing agent [9-12]. Although the developed method 
of preparation and modification of SATs gives high results of adhesive and mechanical properties, in recent years a very strong emphasis has been placed on waste-free technologies. UV-initiated polymerization fits very well with this global trend. Nowadays, UV technology uses a convenient light sources (light-emitting diodes (LEDs), household lamps, LED bulbs, and the sun) [13] and photopolymerization reactions are encountered in various experimental conditions, i.e., in film [14,15], (micro)heterogeneous media or solid state [16,17], on surface [18-20], in ionic liquids [21,22], in situ for the manufacture of microfluidic devices [23,24], and under magnetic field [25]. Relatively rarely the photopolymerization method is used to obtain a liquid polymer or polymer solutions. Admittedly, in the last decade several publications have been published 'regarding the method of obtaining acrylate syrups via the photoinduced polymerization process that occurs in large amounts of monomers' mixture and with a mechanical mixing [26-32]. Obtained products were mainly used as transparent pressure-sensitive adhesives. Nevertheless, the authors did not raise the issue of the impact of photoinitiators (type, quantity) or other factors on the photopolymerization in the bulk (mass) process itself. Type I photoinitiators, especially $\alpha$-hydroxyketones and acylphosphine derivatives, are widely used in industry for coatings' forms [33,34], although initiatorless photopolymerization processes are also realized as well [35]. Nevertheless, current research is focusing on new photoinitiators in photopolymerization processes of acrylates, i.e., bis-silyl ketone [36] or novel phosphine oxides [37,38].

The work presented here demonstrates a new, ecological (without solvent), and rapid method of obtaining a photoreactive acrylic resins (acrylic syrups (ASs)) as the main component of structural adhesives in the form of thermally curable structural adhesives' tapes. The main intention of the authors was to determine the influence of the commercial radical photoinitiator type ( $\alpha$-hydroxyketones, acylphospine oxides and its mixtures) on the polymerization process of (meth)acrylate monomers carried out in large volume of monomers' mixture and under the influence of mechanical mixing (free-radical bulk-photopolymerization (FRBP) process). The purpose of the work was to demonstrate that the type of radical photoinitiator for the FRBP processes has a key impact on the characteristics of obtained products (i.e., ASs). Moreover, the influence of ASs' features on the adhesive, mechanical, and thermal properties of the prepared SATs was investigated as well.

\section{Materials and Methods}

\subsection{Materials}

The following components were used for preparation of acrylic syrups: n-butyl acrylate (BA), butyl methacrylate (BMA), 2-hydroxyethyl acrylate (HEA) (BASF, Ludwigshafen, Germany), glycidyl methacrylate (GMA) (Dow Europe GmbH, Horgen, Germany) and 4-acryloyloxy benzophenone (ABP) (Chemitec, Scandiccy, Italy). As radical photoinitiators type I were tested:

(1) $\alpha$-Hydroxyalkylphenones (HPs):

- 2-hydroxy-1-(4-(4-(2-hydroxy-2-methylpropionyl)benzyl)phenyl)-2-methylpropan-1-one (Omnirad 127; IGM Resin, Waalwijk, The Netherlands).

- 1-hydroxycyclohexylphenyl ketone (Omnirad 184, IGM Resins, Waalwijk, The Netherlands).

(2) Acylphosphine oxides (APOs):

- 2,4,6-trimethylbenzoyl-diphenyl phosphine oxide (Omnirad TPO; IGM Resins, Waalkwijk, The Netherlands).

- $\operatorname{Bis(2,4,6-trimethylbenzoyl)-phenylphosphineoxide~(Omnirad~819;~IGM~Resins,~Waalkwijk,~}$ The Netherlands).

(3) Mixtures of HPs and APOs: 
- Omnirad 2100 (IGM Resins, Waalkwijk, The Netherlands), a blend of ethyl phenyl(2,4,6-trimethylbenzoyl)phosphinate (ca. $95 \mathrm{wt.} \%$ and phenyl bis(2,4,6-trimethylbenzoyl)-phosphine oxide (ca. $5 \mathrm{wt} . \%$ ).

- Omnirad 2022 (IGM Resins, Waalkwijk, The Netherlands), a blend of 2-hydroxy-2-methylpropiophenone (ca. $75 \mathrm{wt} . \%)$, phenyl bis(2,4,6-trimethylbenzoyl)phosphine oxide (ca. $17.5 \mathrm{wt} . \%)$ and ethyl phenyl(2,4,6-trimethylbenzoyl)phosphinate (ca. 7.5 wt.\%).

The structures of tested radical photoinitiators are presented in Table 1. The monomers and initiators were applied without purification.

Table 1. Structures of tested photoinitiators (PI).

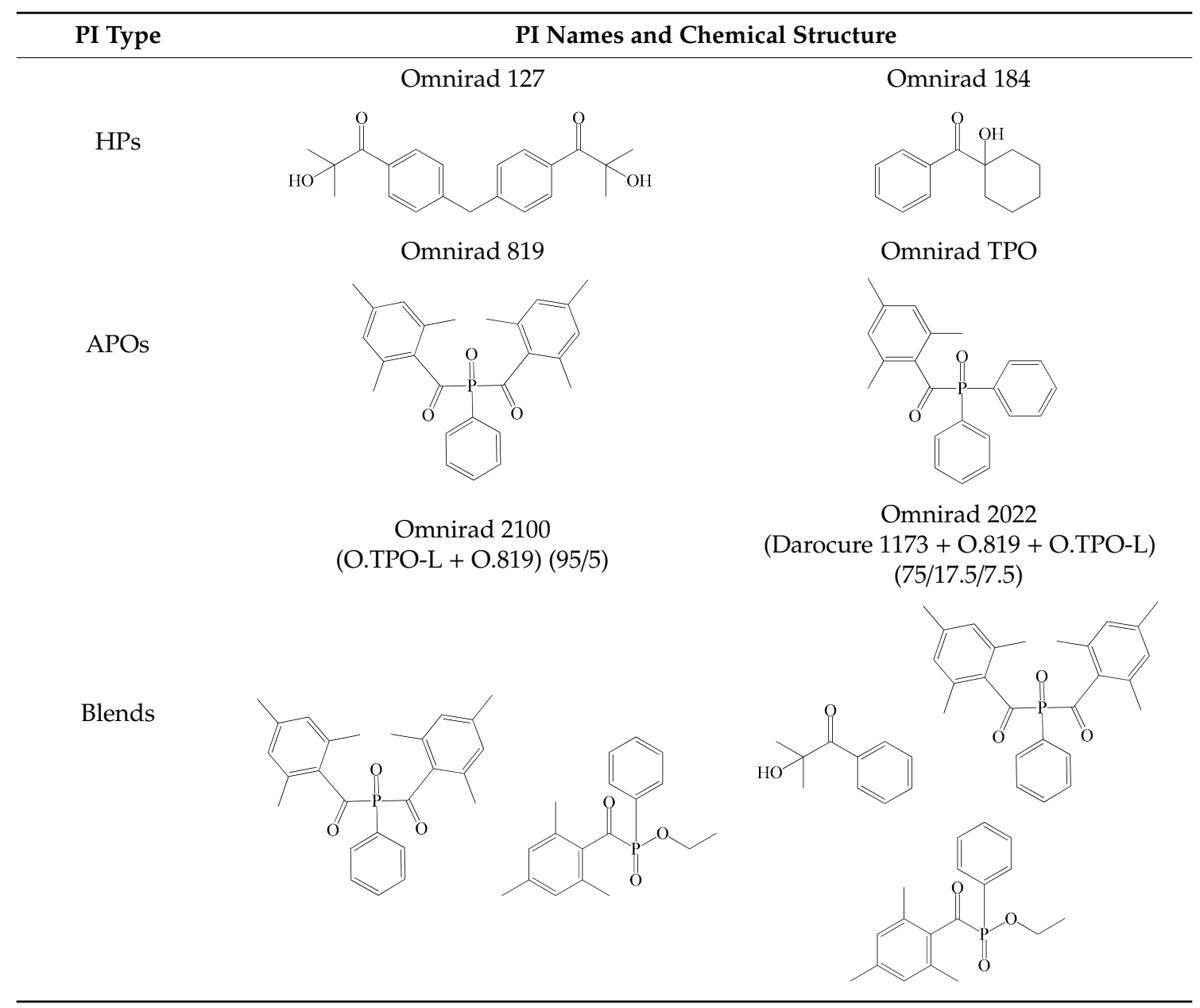

The thermally curable double-sided structural self-adhesive tapes (SATs) were compounded using the AS, the Bisphenol A-based liquid epoxy resin with epoxy equivalent weight of ca. 202 g/equiv. and viscosity $25 \mathrm{~Pa} \cdot \mathrm{s}$ (Epidian; Ciech Sarzyna, Nowa Sarzyna, Poland), photoinitiator Omnirad 127 (IGM Resin, Waalwijk, The Netherlands), multifunctional monomer Laromer 9023 (BASF, Ludwigshafen, Germany), the Lewis acid adduct (Nacure Super Catalyst A218; Worleé Chemie, Hamburg, Germany) as latent curing agent, and Byk 4510 (Byk-Chemie, Wesel, Germany) as adhesion promoter.

\subsection{Synthesis of Acrylic Syrups}

The acrylic syrups (ASs) were prepared via free-radical bulk-photopolymerization process (FRBP) of BA ( $6 \mathrm{~mol})$, BMA (2 mol), GMA (1 mol), HEA ( $1 \mathrm{~mol})$, and ABP $(0.1 \mathrm{~mol})$ using 0.1 or $0.2 \mathrm{~mol}$ of photoinitiator (HPs/APOs or blends). Choice of monomers results from the work carried out previously 
by the authors. Each of the monomers plays a role in the system, i.e., BA, self-adhesive properties; BMA positively influences the FRBP process and increases the glass transition temperature of the copolymers; GMA and HEA take part in the thermal curing reaction with epoxy resin; and ABP, copolymerizing photoinitiator, takes part in the formation of cross-linked poly(meth)acrylate network (at the stage of preparing the SAT). Chemical structures of monomers' and synthesizers' copolymer chain are shown in Figure 1. The copolymerization processes were realized at $20^{\circ} \mathrm{C}$ for 60 or $120 \mathrm{~min}$ in a glass reactor $(250 \mathrm{~mL})$, equipped with a mechanical stirrer and thermocouple, and in the presence of argon as an inert gas. A mixture of monomers $(50 \mathrm{~g})$ was introduced into the reactor and purged with argon for 20 min. The high-intensity UV lamp (UVAHAND 250, Dr. Hönle AG UV Technology, Gräfelfing, Germany) as a UV radiation source was used and it was placed perpendicularly to the side wall of the reactor. The UV irradiation inside the reactor $\left(10 \mathrm{~mW} / \mathrm{cm}^{2}\right)$ was controlled with UV-radiometer SL2W (UV-Design, Brachttal, Germany). The reactor was water-cooled. The reaction was carried out for $60 \mathrm{~min}$.
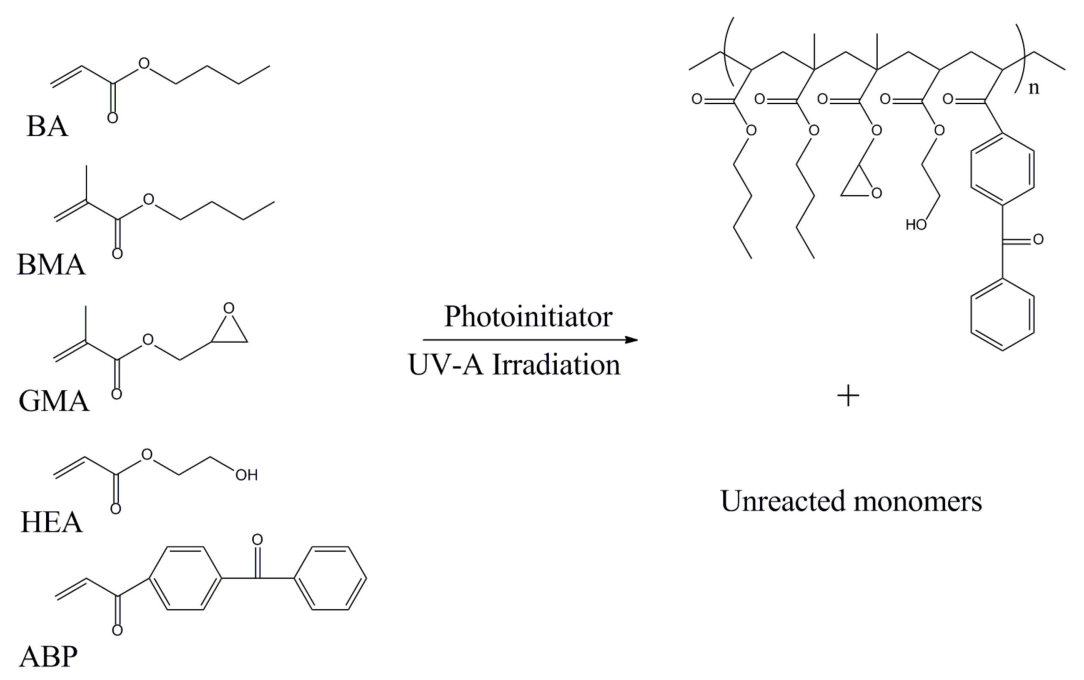

Unreacted monomers

Figure 1. Chemical structures of monomers and synthesis of acrylic syrups.

Nevertheless, if monomer conversion was $<<0.1 \mathrm{~Pa} \cdot \mathrm{s}$ after $60 \mathrm{~min}$, the reaction was repeated and conducted for $120 \mathrm{~min}$ with twice the amount of photoinitiator. Compositions of ASs are presented in Table 2.

Table 2. Compositions of monomers and photoinitiators for preparation of acrylic syrups (ASs).

\begin{tabular}{cccccccc}
\hline \multirow{2}{*}{$\begin{array}{c}\text { AS } \\
\text { Acronym }\end{array}$} & \multicolumn{6}{c}{ Monomers (mol \%) } & \multicolumn{2}{c}{ PI } \\
\cline { 2 - 7 } & BA & BMA & GMA & HEA & ABP & Name & Mol \% \\
\hline AS-127/1 & 58.8 & 19.6 & 9.8 & 9.8 & 0.98 & Omnirad 127 & 1 \\
AS-127/2 & 58.2 & 19.4 & 9.7 & 9.7 & 1 & Omnirad 127 & 2 \\
AS-184/1 & 58.8 & 19.6 & 9.8 & 9.8 & 0.98 & Omnirad 184 & 1 \\
AS-184/2 & 58.2 & 19.4 & 9.7 & 9.7 & 1 & Omnirad 184 & 2 \\
AS-TPO/1 & 58.8 & 19.6 & 9.8 & 9.8 & 0.98 & Omnirad TPO & 1 \\
AS-TPO/2 & 58.2 & 19.4 & 9.7 & 9.7 & 1 & Omnirad TPO & 2 \\
AS-819/1 & 58.8 & 19.6 & 9.8 & 9.8 & 0.98 & Omnirad 819 & 1 \\
AS-2100/1 & 58.8 & 19.6 & 9.8 & 9.8 & 0.98 & Omnirad 2100 & 1 \\
AS-2022/1 & 58.8 & 19.6 & 9.8 & 9.8 & 0.98 & Omnirad 2022 & 1 \\
AS-2022/2 & 58.2 & 19.4 & 9.7 & 9.7 & 1 & Omnirad 2022 & 2 \\
\hline
\end{tabular}

BA—n-butyl acrylate; BMA—butyl methacrylate; GMA—glycidyl methacrylate; HEA—2-hydroxyethyl acrylate; $\mathrm{ABP}-4$-acryloyloxy benzophenone. 
Characterization of the Acrylic Syrups

Dynamic viscosity of the ASs was measured at $23^{\circ} \mathrm{C}$ by means of DV-II Pro Extra viscometer (spindle \#6 or \#7, 50 rpm; Brookfield, New York, NY, USA). Solid content in ASs after FRBP process was determined using Moisture Analyzer MA 50/1.X2.IC.A (Radwag, Radom, Poland). Samples (ca. $2 \mathrm{mg}$ ) were heated in aluminum scale pans at the temperature of $105^{\circ} \mathrm{C}$ for $4 \mathrm{~h}$.

Monomers' conversion after FRBP process was determined by proton nuclear magnetic resonance ${ }^{1} \mathrm{H}$ NMR (Bruker DPX Avance III HD Spectrometer; $400 \mathrm{MHz}$ ). Naphthalene as internal standard was used, and samples of ASs were dissolved in $\mathrm{CDCl}_{3}$. The conversion of monomers were determined by comparing the intensity of monomer peaks at $5.81 \mathrm{ppm}$ (BA), $5.55 \mathrm{ppm}$ (BMA), $5.61 \mathrm{ppm}$ (GMA), $5.88 \mathrm{ppm}$ (HEA), and $6.65 \mathrm{ppm}(\mathrm{ABP})$ against the intensity of peaks of the internal standard at $7.5 \mathrm{ppm}$ and $7.8 \mathrm{ppm}$ (naphthalene). The solid content in acrylic syrups was determined using the thermogravimetric method $\left(105{ }^{\circ} \mathrm{C} / 4 \mathrm{~h}\right.$; moisture analyzer Radwag MA 50.R, Radwag, Radom, Poland).

Gel permeation chromatography (GPC) was used to determine molecular masses $\left(M_{w}, M_{n}\right)$ and polydispersity (PDI) of the copolymers (acrylic syrups were dried at $140{ }^{\circ} \mathrm{C}$ for $4 \mathrm{~h}$ before the test to remove unreacted monomers). The GPC apparatus contained the refractive index detector (Merck Lachrom RI L-7490), pump (Merck Hitachi Liquid Chromatography L-7100), and interface (Merck Hitachi Liquid Chromatography D-7000) and the Shodex OHpak SB-806M MQ column with Shodex OHpak SB-G precolumn. The GPC tests were performed using polystyrene standards (Fluka and Polymer Standards Service GmbH, Mainz, Germany) and tetrahydrofurane.

\subsection{Preparation and Characterization of Self-Adhesive Structural Tapes (SATs) and Al/SAT/Al Joints}

The SATs were compounded using the AS (50 wt parts), the epoxy resin (50 wt parts), the latent curing agent (1.5 wt part), multifunctional monomer ( $2 \mathrm{wt}$ part), photoinitiator Omnirad 127 (3 wt part), and adhesion promoter ( $0.75 \mathrm{wt}$ part). The addition of multifunctional monomer and photoinitiator was to increase the cross-link density of the system. The preparing steps of SATs are shown in Figure 2.

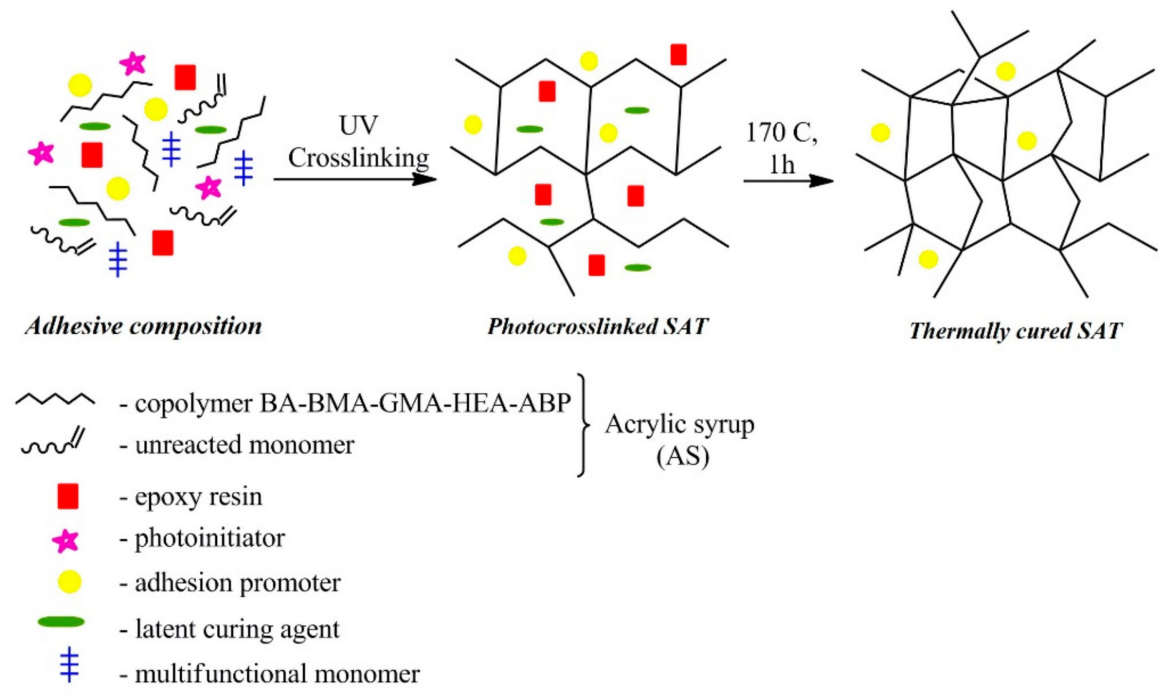

Figure 2. Preparation steps of the self-adhesive structural tapes (SATs).

The compositions were applied onto polyester foils (samples for self-adhesive tests) or siliconized paper (other tests) and UV irradiated for $30 \mathrm{~s}\left(8 \mathrm{~J} / \mathrm{cm}^{2}\right)$ using the medium pressure mercury lamp (UV-ABC; Hönle UV-Technology, Gräfelfing, Germany). The UV exposition was controlled with the radiometer (Dynachem 500; Dynachem Corp., Westville, IL, USA). Thickness of the UV-photo cross-linked SATs' layers were $120 \mu \mathrm{m}$. Self-adhesive properties of the thermally uncured SATs were tested according to AFERA 4001 (adhesion to a steel substrate) and AFERA 4015 (tack). These 
parameters were evaluated using three samples of each adhesive tape. Differential scanning calorimetry (DSC Q100, TA Instruments, New Castle, DE, USA) was used for determination of the glass transition temperature $\left(T_{\mathrm{g}}\right)$ of the SATs, enthalpy of SAT curing processes $(\Delta H)$, onset temperature of the curing reactions $\left(T_{\mathrm{i}}\right)$, and maximum temperature of the curing reaction $\left(T_{\mathrm{p}}\right)$. Samples (ca. $10 \mathrm{mg}$ ) were analyzed using standard aluminum pans at the temperature range of -80 to $350{ }^{\circ} \mathrm{C}$ (heating rate of $10^{\circ} \mathrm{C} / \mathrm{min}$ ). Two DSC measurements for each composition were carried out.

Aluminum-SAT-aluminum overlap joints (Al/SAT/Al) were prepared using the SATs and degreased 2024 aluminum panels $(100 \times 25 \times 1.6 \mathrm{~mm})$. The joints were thermally cured at $170{ }^{\circ} \mathrm{C}$ for $60 \mathrm{~min}$. Shear strength of the Al/SAT/Al systems was measured at room temperature according to the ASTM D1002-10 standard (10 samples of each system) using the Z010 machine (Zwick/Roell, Ulm, Germany). Cross-linking degree $(\alpha)$ of thermally cured SATs was calculated using DSC data according to Equation (1) [39]

$$
\alpha=\left(\frac{\Delta H_{T}-\Delta H_{\text {res }}}{\Delta H_{T}}\right) \text { (a.u.) }
$$

where $\Delta H_{T}$ is the total enthalpy of the SAT curing process $(\mathrm{J} / \mathrm{g})$ and $\Delta H_{\text {res }}$ is the enthalpy of a postcuring process of the thermally cured SAT (in a Al/SAT/Al joint).

Dynamic mechanical analysis (DMA) was performed by using the DMA Q800 (TA Instruments, USA). The testing configuration was the dual cantilever mode, with the nominal sample dimension of $50 \times 10 \times 2 \mathrm{~mm}$ and a heating ramp of $3{ }^{\circ} \mathrm{C} / \mathrm{min}$. All tests were performed by setting $20 \mu \mathrm{m}$ as the amplitude and $1 \mathrm{~Hz}$ as the frequency. For thermal (DSC) and thermo-mechanical (DMA) properties, three tests for each sample were performed.

\section{Results}

\subsection{Properties of the Acrylic Syrups}

Selected physico-chemical features (i.e., viscosity, solid content, and molecular masses) of the ASs are presented in Table 3. As can been seen, four syrups (i.e., AS-127/1, AS-184/1, AS-TPO/1, and AS-2022/1) exhibited markedly low viscosity $(<<0.1 \mathrm{~Pa})$, which is insufficient due to further applications. PleaThree of these syrups was obtained using HP-type photoinitiators (Omnirad 127, Omnirad 184 and Omnirad 2022; the last one contains about 75 wt. $\%$ of $\alpha$-hydroxyalkylphenone Darocure 1173). It should be noted that ASs obtained using higher dose (2 mol \%) of HPs (i.e., AS-127/2, AS-184/2) also exhibited low viscosity value (1 and $1.5 \mathrm{~Pa} \cdot \mathrm{s}$, respectively). Interestingly, the viscosity of the sample with a blend of PIs (AS-2022/2, where weight ratio of HP to APO was 70/30) was only $0.1 \mathrm{~Pa} \cdot \mathrm{s}$. The viscosity measurements' results correlated with the solid content test. As can be seen in Table 3, the solid content values for ASs with HP-type photoinitators were lower than others (45 and $49 \mathrm{wt} . \%$ for AS-127/2 and AS-184/2, respectively), whereas AS-2022/2 sample reached only $20 \mathrm{wt} . \%$ of the analyzed parameter. It should be noted that the viscosity and solid content values correlated with GPC measurements' data. The AS-127/2 and AS-184/2 samples with almost the same viscosity and solid content values exhibited very similar results of $M_{n}$ (ca. 13,000 g/mol), $M_{w}(47,000 \mathrm{~g} / \mathrm{mol})$, and PDI (3.5 a.u.). The lowest values of molecular weights were detected for AS with Omnirad 2022 (blend of HPs and APO) and $M_{n}$ amounted to $4800 \mathrm{~g} / \mathrm{mol}$ and $M_{w}$ to $22,100 \mathrm{~g} / \mathrm{mol}$. Generally, the performed tests proved the adverse effect of photoinitiator mixtures (especially HPs with APO) on the rheological properties of syrups. As can be seen in Table 3, the ASs prepared using APO-type photoinitiators exhibited higher viscosity and solid content than samples with HPs. The viscosity and solid content for AS-TPO/2 were markedly higher (33 Pa.s and $73 \mathrm{wt} . \%$, respectively), but to prepare this syrup $2 \mathrm{~mol} \%$ of PI was used and UV irradiation time was $120 \mathrm{~min}$. Nevertheless, the molecular weights values were similar as those for the sample with HPs. Higher results of $M_{n}$ and $M_{w}$ values were obtained in the case of the sample with Omnirad 819 (16,800 g/mol; 55,100 g/mol) and Omnirad 2100 (20,000 g/mol; 67,500 g/mol). This effect was probably due to the generation of four radicals per Omnirad 819 molecule [40]. Also, the system (AS-2100) containing the mixture of photoinitiators was multi-radical. For this reason, higher molecular 
weights were obtained. It should be emphasized that all copolymers (prepared from ASs) did not have a unimodal molecular weight distribution. The PDI values amounted to ca. 3.5 a.u., whereas in the case of the sample with the blend of HPs and APO (AS-2022) this value was even higher, i.e., 4.61 a.u.

Table 3. Dynamic viscosity, solid content, and molecular weights of ASs.

\begin{tabular}{cccccc}
\hline AS Symbol & $\boldsymbol{\eta} \mathbf{( P a} \cdot \mathbf{s})$ & Solid Content $\mathbf{( w t} \%)$ & $\boldsymbol{M}_{\mathbf{n}} \mathbf{( g / \mathbf { m o l } )}$ & $\boldsymbol{M}_{\mathbf{w}} \mathbf{( g / m o l )}$ & PDI \\
\hline AS-127/1 & $<0.1$ & n.d. & n.d. & n.d. & n.d. \\
AS-127/2 & 1.0 & 45 & 13,170 & 47,100 & 3.58 \\
AS-184/1 & $<0.1$ & n.d. & n.d. & n.d. & n.d. \\
AS-184/2 & 1.5 & 49 & 13,850 & 48,400 & 3.5 \\
AS-TPO/1 & $<0.1$ & n.d. & n.d. & n.d. & n.d. \\
AS-TPO/2 & 33 & 73 & 13,550 & 48,100 & 3.55 \\
AS-819/1 & 14.0 & 66 & 16,800 & 55,100 & 3.28 \\
AS-2100/1 & 6.5 & 58 & 20,000 & 67,500 & 3.38 \\
AS-2022/1 & $<0.1$ & n.d. & n.d. & n.d. & n.d. \\
AS-2022/2 & 0.1 & 20 & 4800 & 22,100 & 4.61 \\
\hline
\end{tabular}

n.d.-no data; $\eta$-viscosity; $M_{\mathrm{n}}$-number average molecular weight; $M_{\mathrm{w}}$-weight average molecular weight; PDI—polydispersity.

It has long been noted that the photoinitiator efficiency varies depending on the formulation (composition with monomers) and a photoinitiator can be more efficient in one system but not in another [41]. Moreover, the matching of the PIs' absorption spectrum with emission spectrum of the light source is crucial [42]. It is known that APO-type photoinitiators (especially Omnirad TPO and Omnirad 819) strongly absorb in the UV-A region ( $\lambda_{\max }$ ranging between 365 and $416 \mathrm{~nm}$ ) [34] and HP-type PIs can be activated by lamps emitting up to $380 \mathrm{~nm}$ [40]. The UV lamp used for testing emits only UV-A radiation (320-390 nm), so matching the tested PIs to UV source seems to be correct. As we mentioned, there are no photoinitiators dedicated to mass/bulk-photopolymerization processes (FRBP). However, among the products available on the market, APOs proved to be appropriate because they are excellent at facilitating depth cure in coatings. The researchers revealed that the number of radicals generated from the photoinitiator is of great importance in the FRBP process. Photoinitiators generating more than two kinds of radicals (like Omnirad 819 and Omnirad 2100) have been found to be more suitable for FRBP process because they allow syrups with higher viscosities and molecular weights to be obtained.

The influence of PIs' type on the monomer conversion in multi-component systems has not been widely described in the literature. The present research on ASs' preparation should be considered as pioneering in this field. In Figure 3, the stacked plots of the ${ }^{1} \mathrm{H}$ NMR spectra of acrylic syrups are presented. 


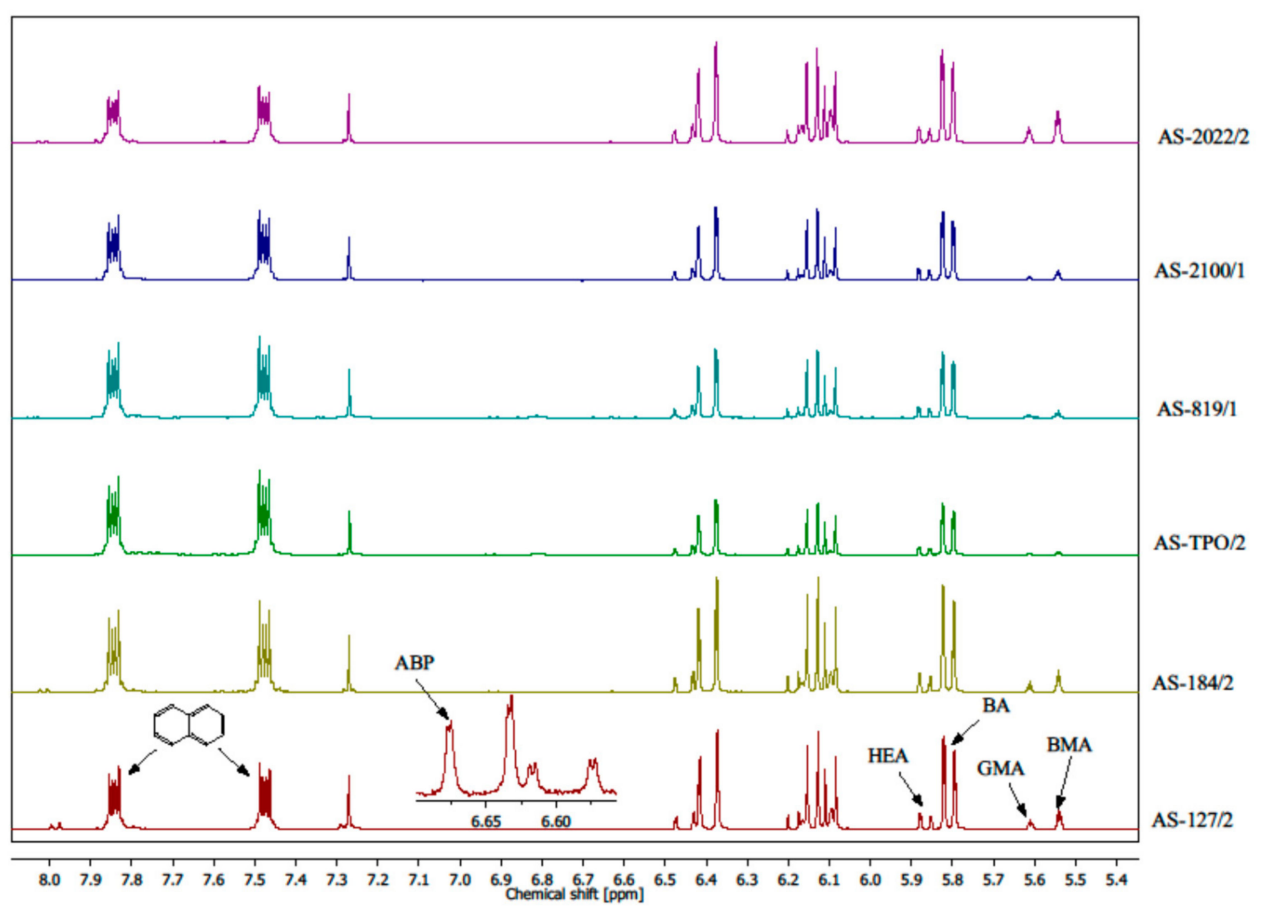

Figure 3. Stacked plot of the proton nuclear magnetic resonance $\left({ }^{1} \mathrm{H}\right.$ NMR) spectra of acrylic syrups. Peaks monitored for each monomer and the internal standard (naphthalene) are indicated.

The monomers' conversion (C- total conversion and conversion of individual monomers) are presented in Table 4.

Table 4. Monomers' conversion calculated by proton nuclear magnetic resonance $\left({ }^{1} \mathrm{H}\right.$ NMR $)$ analyses.

\begin{tabular}{ccccccc}
\hline \multirow{2}{*}{ AS Symbol } & \multicolumn{7}{c}{ Monomers Conversion (\%) } \\
\cline { 2 - 7 } & C $^{\mathbf{1}}$ & BA & BMA & GMA & HEA & ABP \\
\hline AS-127/2 & 45 & 35 & 66 & 68 & 30 & 65 \\
AS-184/2 & 52 & 42 & 72 & 73 & 38 & 68 \\
AS-TPO/2 & 75 & 65 & 94 & 95 & 67 & 89 \\
AS-819/1 & 68 & 57 & 90 & 90 & 57 & 88 \\
AS-2100/1 & 62 & 50 & 85 & 86 & 50 & 79 \\
AS-2022/2 & 23 & 17 & 38 & 36 & 11 & 37 \\
\hline & \multicolumn{7}{c}{ C is total monomers' conversion. }
\end{tabular}

As can be seen, the total monomers' conversion values (C) are similar to those determined by thermogravimetric method (solid content values in Table 3). The highest results exhibited AS-TPO/2 $(75 \%)$ and AS-819/1 (68\%). As the conversion of an individual monomer is concerned, it can be seen that very high conversion of BMA and GMA was achieved in systems with APO-type PIs. BMA conversion amounted to 94\% (using Omnirad TPO), 90\% (Omnirad 819), and 85\% (Omnirad 2100) and GMA conversion reached 95,90 , and $89 \%$ (in the same order). The conversion of ABP was very high as well (79-89\%). Generally, in all syrups the conversion of methacrylate monomers (BMA and GMA) was almost two-fold higher than that of acrylate monomers (BA and HEA). NMR studies have shown that ASs consisted of copolymer part and unreacted monomers' mixture, mainly BA and HEA. According to NMR measurements, data could be calculated (not presented) such that ASs with APO-type PIs (AS-TPO/2, AS-819/1, and AS-2100/1) contained a copolymer BA-BMA-GMA-HEA-APB (in which the molar ratio of monomers was ca. 4/1.9/1.9/0.7/0.09, respectively) and mixtures of unreacted BA (ca. $2 \mathrm{~mol}$ ) and HEA (ca. $0.3 \mathrm{~mol}$ ). In contrast, acrylic syrups based on HP-type PIs and HPs/APO blend (AS-Omnirad 2022), in addition to unreacted BA and HEA, contained a lot of BMA and GMA as well. 


\subsection{Properties of Thermally Uncured SATs Based on Acrylic Syrups}

Based on the prepared ASs and the commercial epoxy resin (ER), the thermally curable pressure-sensitive adhesive films (SATs) were prepared. In this paper, we are presenting a new, solvent-free method of obtaining the SATs, i.e., preparing the adhesive binder (epoxyacrylate copolymer) via FRBP process. Thermal curing process of the SATs (based on the ASs' components) are presented in Table 5 and Figure 4. As can be seen, the SATs exhibited one $T_{\mathrm{g}}$ value. This confirmed that the ingredients (ER and methacrylate copolymers) were thermodynamically miscible. The $T_{\mathrm{g}}$ values were quite similar $\left(-10^{\circ} \mathrm{C},-11^{\circ} \mathrm{C}\right.$, or $\left.-12^{\circ} \mathrm{C}\right)$, but it should be emphasized that SATs received using the HP-type PIs (SAT-127, SAT-184, and SAT-2022) characterized a bit lower $T_{\mathrm{g}}$ value $\left(-12{ }^{\circ} \mathrm{C}\right)$ than others. Interestingly, the mentioned SATs exhibited markedly higher enthalpy of cationic curing process of epoxy groups $(\Delta H)(247 \mathrm{~J} / \mathrm{g}, 233 \mathrm{~J} / \mathrm{g}$, and $253 \mathrm{~J} / \mathrm{g}$, respectively) as well as lower onset temperature of the process $\left(T_{\mathrm{i}}\right)\left(120^{\circ} \mathrm{C}, 135^{\circ} \mathrm{C}\right.$, and $136{ }^{\circ} \mathrm{C}$, respectively). Arguably, this effect was related to the properties of the acrylic syrups. AS-127, AS-184, and AS-2022 were characterized by lower monomer conversion (23-52\%, Table 4) than ASs with APO-type PIs (62-75\%) as well as lower molecular masses (Table 3). As we stated in this paper, AS-127, AS-184, and AS-2022 syrups contained few low-molecular copolymers of BA-BMA-GMA-HEA-ABP and all types of unreacted monomers.

Table 5. Thermal features of uncured self-adhesive tapes (SATs) based on ASs and cross-linking degree of cured SATs.

\begin{tabular}{cccccc}
\hline SAT Acronym & $\boldsymbol{T}_{\mathbf{g}}\left({ }^{\circ} \mathbf{C}\right)$ & $\boldsymbol{T}_{\mathbf{i}}\left({ }^{\circ} \mathbf{C}\right)$ & $\boldsymbol{T}_{\mathbf{p}}\left({ }^{\circ} \mathbf{C}\right)$ & $\boldsymbol{\Delta H}(\mathbf{J} / \mathbf{g})$ & $\boldsymbol{\alpha}(\mathbf{a . u .})$ \\
\hline SAT-127 & -12 & 120 & 194 & 247 & 0.87 \\
SAT-184 & -12 & 135 & 195 & 233 & 0.81 \\
SAT-TPO & -11 & 167 & 210 & 224 & 0.59 \\
SAT-819 & -11 & 149 & 206 & 209 & 0.67 \\
SAT-2100 & -10 & 138 & 192 & 223 & 0.81 \\
SAT-2022 & -12 & 136 & 191 & 253 & 0.88 \\
\hline
\end{tabular}

$T_{\mathrm{g}}$-glass transition temperature; $T_{\mathrm{i}}$-onset temperature of the curing reactions; $T_{\mathrm{p}}$-maximum temperature of the curing reaction; $\Delta H$-enthalpy of SAT curing processes; $\alpha$-cross-linking degree of thermally cured SATs.

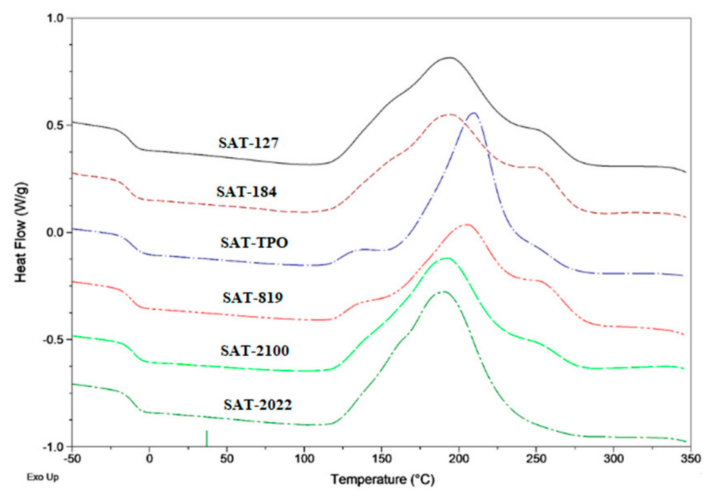

(a)

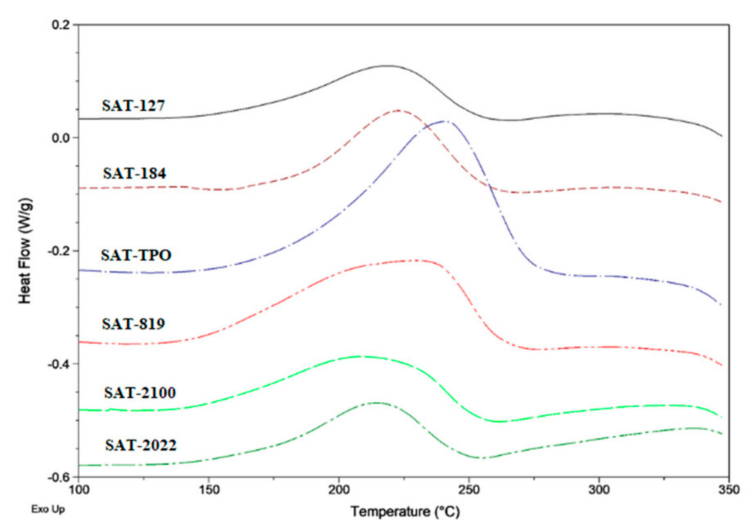

(b)

Figure 4. Differential scanning calorimetry (DSC) thermographs for the uncured SATs (a) and cured SATs (b) based on ASs.

Probably, on the SAT preparation stage, during UV irradiation in the presence of ER and other ingredients from unreacted monomers, low-molecular products (methacrylate copolymers) were formed. Instead, the process of polymerization of epoxy groups (at the stage of aluminum joints' preparation; the curing process in high temperature) was easier (lower $T_{\mathrm{i}}$ and higher $\Delta H$ ) in the presence of low-molecular copolymers (formed at the stage of preparing the adhesive film). The opposite effect 
was in the case of SAT with APO-type PIs. The characteristic temperatures of cationic polymerization of epoxy groups $\left(T_{\mathrm{i}}\right.$ and $T_{\mathrm{p}}$ ) were higher, i.e., $167^{\circ} \mathrm{C}$ and $210^{\circ} \mathrm{C}$ (for SAT-TPO) and $149^{\circ} \mathrm{C}$ and $206^{\circ} \mathrm{C}$ (for SAT-819). However, enthalpy values were lower (209 J/g for SAT-TPO and $223 \mathrm{~J} / \mathrm{g}$ for SAT-819). An additional confirmation of this effect of syrups was the result of the cross-linking degree ( $\alpha$, Table 5$)$. Cross-linking degree measurements (DSC) were performed for thermally cured SATs. Generally, a higher $\alpha$ value was demonstrated for SAT received using the HP-type PIs (from 0.81 to 0.88 a.u.) than SAT with APOs (0.50 for SAT-TPO and 0.67 for SAT-819). The highest values of $\alpha$ were achieved for SAT-2022 (0.88) (HPs/APO blend) received from AS-2022/2 with the lower value of monomers' conversion $(23 \%$, Table 4$)$.

The thermally uncured SATs were characterized in terms of their basic self-adhesive features (i.e., adhesion to a steel and tack). Results are presented in Figure 5. As can be seen, SATs based on APO-type PIs exhibited significantly higher values of adhesion (20 N/25 mm for SAT-TPO; $14 \mathrm{~N} / 25 \mathrm{~mm}$ for SAT-819 and $12 \mathrm{~N} / 25 \mathrm{~mm}$ for SAT-2100) and tack ( $45 \mathrm{~N}, 37 \mathrm{~N}$ and $23 \mathrm{~N}$, respectively). On the other hand, the lowest value of features under discussion was noticed for SAT-2022 $(3.2 \mathrm{~N} / 25 \mathrm{~mm}$ and $12.7 \mathrm{~N})$. It should be noted that SAT-TPO, SAT-819, and SAT-2100 were based on ASs that were characterized by high monomers' conversion (C) and high viscosities compared to ASs with HP-type PIs. Considering the SATs based on APO photoinitiators, it can be seen that adhesion values decreased with increasing $M_{n}$ and $M_{w}$ values in ASs. This was accordance with the literature reports on the effect of molecular weight on adhesion features [43]. However, this interpretation of the effect of photoinitiators on adhesion can only be used in systems with high and similar monomers' conversion. It should be noted that SAT films were prepared on the way of UV irradiation of the mixtures of ASs (with unreacted monomers) and ER (mainly). The aspect of amount of unreacted monomers' mixtures seems to be crucial. The high content of unreacted monomers in the AS/ER system intended for UV cross-linking reduced the adhesive properties (adhesion to a steel and tack) of obtained SAT.

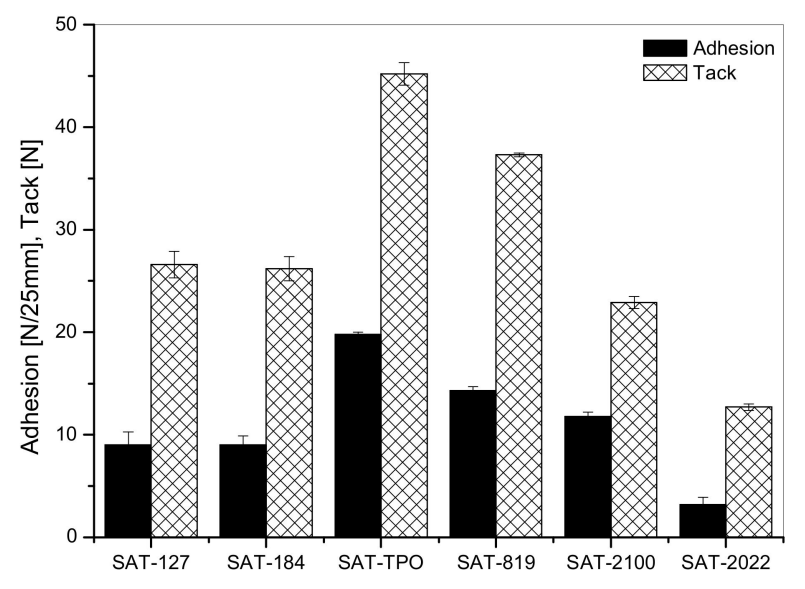

Figure 5. Adhesion to steel and tack for thermally uncured SATs based on ASs.

\subsection{Properties of Thermally Cured SATs Based on Acrylic Syrups}

The SATs were applied onto $2024 \mathrm{~T} 3$ aluminum panels and the prepared Al/SAT/Al overlap joints were thermally cured at $170{ }^{\circ} \mathrm{C}$ for $60 \mathrm{~min}$. Shear strength $(\tau)$ values recorded for the cured joint are presented in Figure 6. As can be observed, the best result (17.1 MPa) was noted for Al/SAT-2100/Al. Joints with SAT-127 and SAT-184 also exhibited high results (14.5 MPa and $15.5 \mathrm{MPa}$, respectively). Interestingly, the Al/SAT-TPO/Al sample reached the lowest value $(9.7 \mathrm{MPa})$ of the parameter. On this basis, it can be concluded that shear strength of SAT films does not depend on adhesion (adhesion of SAT-TPO was the highest and reached $20 \mathrm{~N} / 25 \mathrm{~mm}$ ). In Figure 7 the results of shear strength and cross-linking degree ( $\alpha$, DSC measurements of cured SATs, Table 5$)$ are summarized. As it turned out, there was a certain "optimal" cross-linking degree of adhesive at which the adhesive joint exhibited the highest shear strength. 


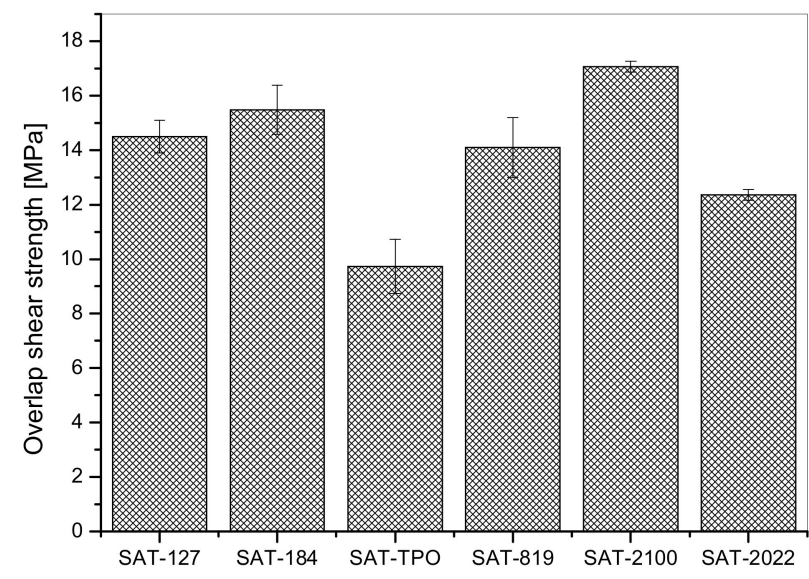

Figure 6. Shear strength for thermally cured aluminum-SAT-aluminum overlap joints.

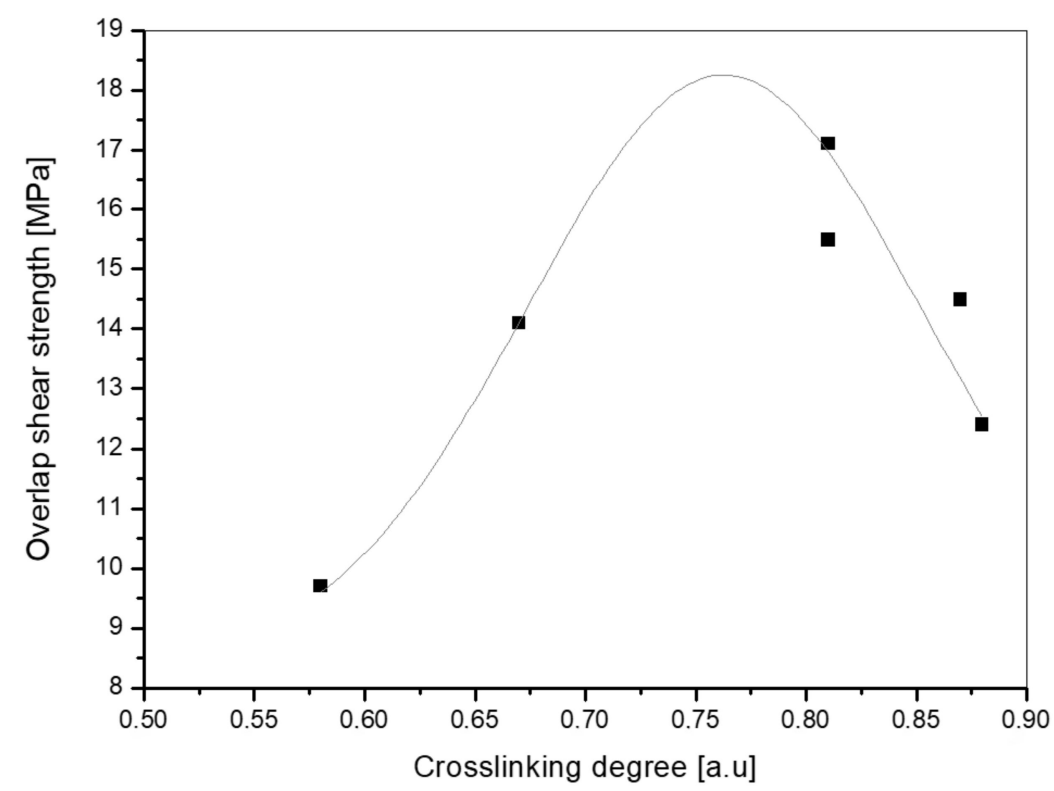

Figure 7. Influence of cross-linking degree ( $\alpha$, DSC measurements) of thermally cured SATs on overlap shear strength for aluminum-SAT-aluminum overlap joints.

In the case of SAT products, it was about 0.7 to 0.8 a.u. The presented results of the influence of cross-linking density on shear strength are consistent with the literature reports [44] and our previous unpublished research.

In the next step, we compared the results of cross-linking degree of cured SATs and monomers' conversion of ASs used for SAT preparation. The results are shown in Figure 8. As can be seen, the cross-linking degree values $(\alpha)$ markedly decreased with increasing the monomers' conversion in ASs. As we mentioned, the highest result of $\tau$ was registered for SAT-2100 (17.1 MPa) and SAT-184 (15.5 MPa) samples, which were characterized by the $\alpha$ values 0.81 and 0.8 (respectively) and total conversion of monomers (C) $62 \%$ (SAT-2100) and 52\% (SAT-184). We assumed that the monomers' conversion interval can be indicated by which the cross-linking degree giving the highest shear strength is obtained. Based on the performed research, we claim that syrups with a ca. 50-60\% of monomers' conversion are of great importance here. 


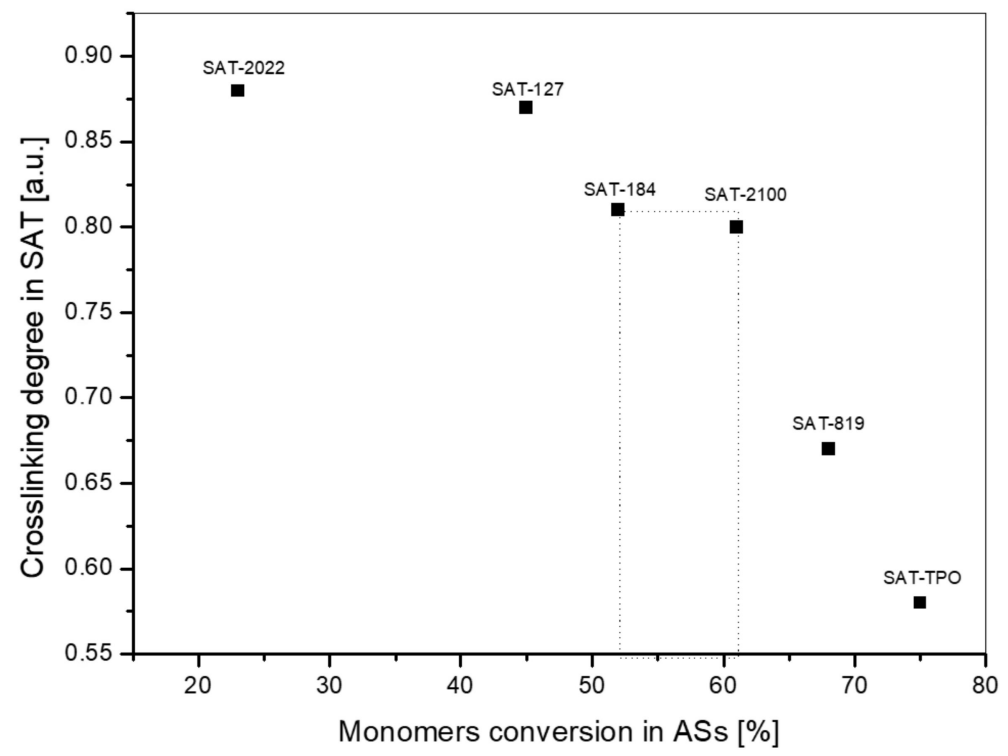

Figure 8. Influence of the monomers' conversion of ASs (C, NMR data) on cross-linking degree (calculated using DSC data) for thermally cured SATs.

The dynamic mechanical properties of SATs based on ASs were examined by DMA in the -90 to $180^{\circ} \mathrm{C}$ temperature range. Figure 9 shows the storage modulus $\left(E^{\prime}\right)$ and Figure 10 shows the tan $\delta$ as a function of temperature. Storage modulus at room temperature and $150{ }^{\circ} \mathrm{C}$ and glass transition temperatures for cured SATs are summarized in Table 6.

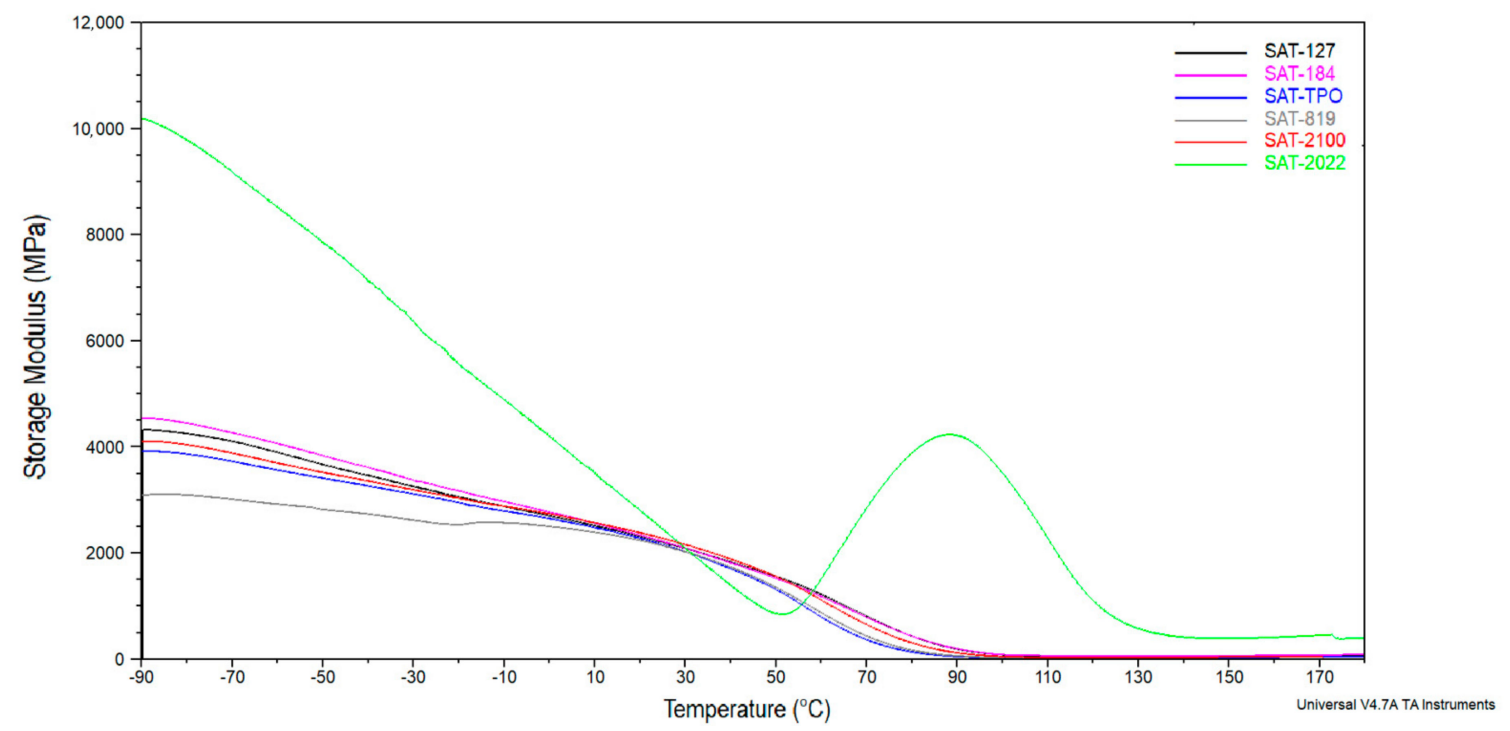

Figure 9. Storage modulus for thermally cured SATs. 


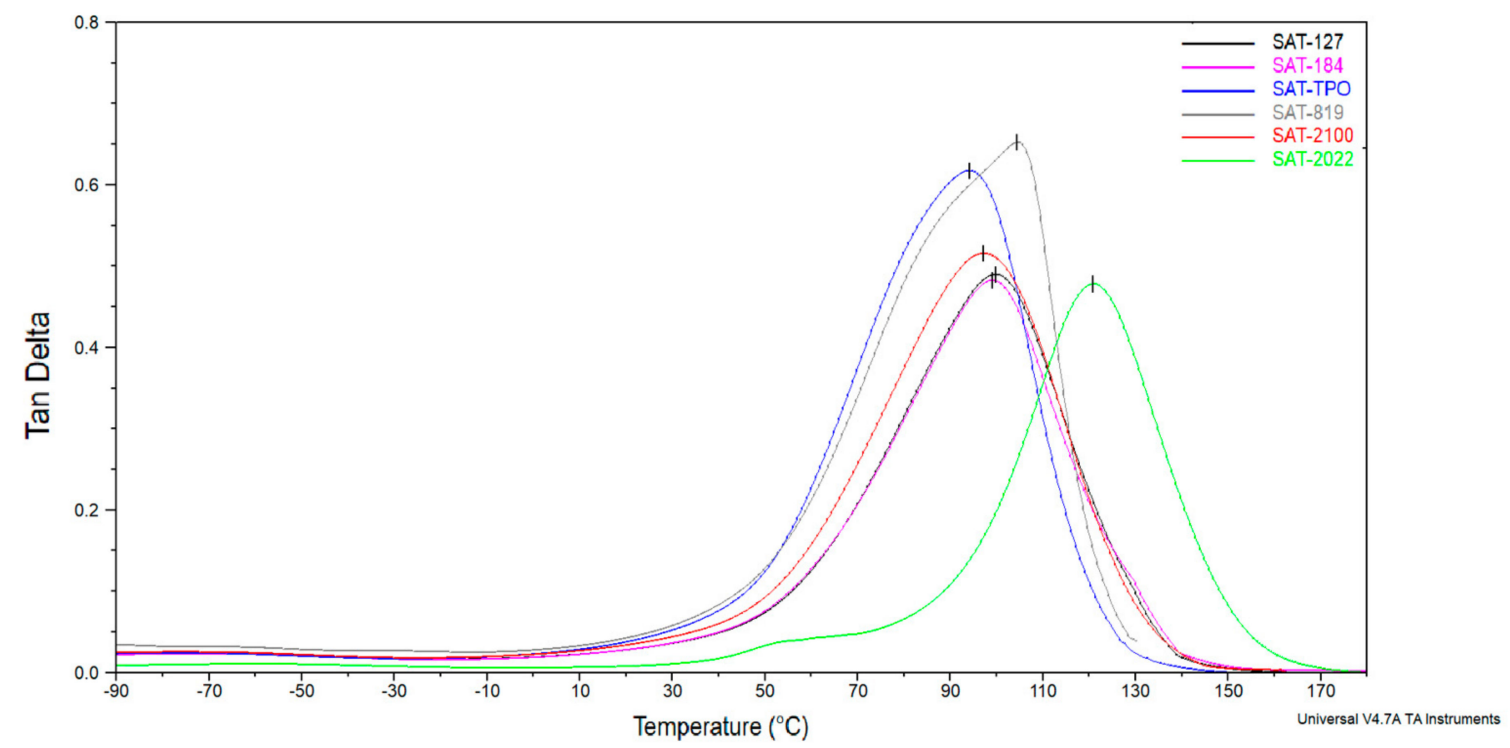

Figure 10. Tangens delta for thermally cured SATs.

Table 6. Characteristic storage modulus $\left(E^{\prime}\right)$ values at room temperature and $150{ }^{\circ} \mathrm{C}$ and the glass transition temperature $\left(T_{\mathrm{g}}\right)$ values for cured SATs based on ASs.

\begin{tabular}{cccc}
\hline SAT & \left.${\boldsymbol{E}^{\prime}}_{\left(\mathbf{2 5}{ }^{\circ} \mathbf{C}\right)} \mathbf{( M P a}\right)$ & \left.${\boldsymbol{E}^{\prime}}_{\left.\mathbf{( 1 5 0}{ }^{\circ} \mathbf{C}\right)} \mathbf{( M P a}\right)$ & $\boldsymbol{T}_{\mathbf{g}}\left({ }^{\circ} \mathbf{C}\right)$ \\
\hline SAT-127 & 2285 & 50 & 100 \\
SAT-184 & 2216 & 58 & 99 \\
SAT-TPO & 2136 & 28 & 94 \\
SAT-819 & 2156 & 20 & 103 \\
SAT-2100 & 2202 & 35 & 96 \\
SAT-2022 & 2454 & 383 & 120 \\
\hline
\end{tabular}

DMA curves for SATs are similar to those for thermosetting epoxy resins. Notwithstanding, DMA analysis revealed differences between SATs in the glassy region (especially in the range of $-90^{\circ} \mathrm{C}$ to $0{ }^{\circ} \mathrm{C}$ ). Probably, the methacrylate copolymers (i.e., ASs) are responsible for maintaining the SATs in the area of low temperatures. It can be seen that all SATs' samples showed similar behavior except for SAT-2022. In this case, the peak on storage modulus curve can be observed (with initial temperature ca. $50{ }^{\circ} \mathrm{C}$ and maximum temperature ca. $89^{\circ} \mathrm{C}$ ), which means that the additional cross-linking reaction occurred. From the literature, cases of additional curing of weakly cross-linked samples during DMA tests are known [45]. We claim that due to the low monomers' conversion of AS-2022 (23\%, Table 4), the formation of short methacrylate chains during UV irradiation and uncured SAT-2022 preparation was possible, so that the cationic cross-linking process of epoxy groups was not disturbed. Therefore, it is possible to supplementary cross-link during the DMA analysis. Our research revealed that cured SAT-2022 exhibited the higher cross-linking degree ( $\alpha=0.88$, after curing at $170{ }^{\circ} \mathrm{C}$ for $\left.60 \mathrm{~min}\right)$, so the storage modulus at room temperature of this sample was higher $(2454 \mathrm{MPa})$ in comparison to other samples (+7-14\%). After additional cross-linking during DMA analysis the value of the storage modulus at $150{ }^{\circ} \mathrm{C}(383 \mathrm{MPa})$ was significantly higher (+660-1915\%). Additionally, the $T_{\mathrm{g}}$ value for SAT-2022 was outstanding $\left(120^{\circ} \mathrm{C}\right.$, Table 6$)$. The $T_{\mathrm{g}}$ values for other SATs were comparable (ca. $\left.100^{\circ} \mathrm{C}\right)$.

\section{Conclusions}

In this paper, the new and environmentally friendly method of obtaining thermally curable structural self-adhesive tapes was presented and the effect of used, different type I photoinitiators on selected features of the obtained acrylic syrups and adhesive and (thermo)mechanical properties of SATs were studied. It was stated that the kind of photoinitiator significantly influenced the physico-chemical 
features of ASs. More suitable are PIs generating more kinds of radicals. Definitely higher results of viscosity, solid content, monomers' conversion, and molecular weight in ASs were obtained when APO-type PIs were used, especially bis(2,4,6-trimethylbenzoyl)-phenylphosphineoxide (Omnirad 819) or its mixtures with 2,4,6-trimethylbenzoyl-diphenyl phosphine oxide (Omnirad 2100). Additionally, ASs obtained using APO-type PIs were characterized by higher adhesive properties (adhesion to a steel and tack). It was found that a higher content of unreacted monomers ( $>50 \mathrm{wt} . \%)$ reduced the adhesive properties of SATs after UV cross-linking but increased the cross-linking degree of SATs after thermal curing. In turn, the cross-linking degree had a decisive impact on shear strength of aluminum-SAT-aluminum joints. The optimal value of the mentioned parameter was indicated (ca. 0.7-0.8 a.u.). In order to achieve this ratio, the ASs with a monomers' conversion of ca. $50-60 \%$ should be prepared. Considering the above, the highest shear strength results were obtained with SAT-184 (prepared with $2 \mathrm{~mol} \%$ of HP-type PI) and SAT-2100 (1 mol \% of APO-type PIs). It seems that kind of PIs does not have a crucial impact on mechanical properties of SATs but the appropriate monomers' conversion is necessary. Nevertheless, the fact is that monomers' conversion in FRBP process on the level of 50-60\% may by already achieved using the $1 \mathrm{~mol} \%$ of APO-type PIs and, in the case of HP-type PIs, $2 \mathrm{~mol} \%$ of initiator is needed. Considering the thermo-mechanical properties of cured SATs, it should be mentioned that they basically differed only in the area of low temperatures. On the other hand, the sample obtained from AS with significantly low monomers' conversion underwent typical postcuring effects during the test and translated into an increase in the glass transition temperature of SAT.

Author Contributions: Conceptualization, A.K. and K.G.; methodology, A.K. and K.G.; investigation, A.K., K.G., and B.S.; writing—original draft preparation, A.K.; writing—review and editing, A.K.; supervision, A.K. All authors have read and agreed to the published version of the manuscript.

Funding: This research received no external funding.

Conflicts of Interest: The authors declare no conflict of interest.

\section{References}

1. Weglewski, J.; Pastirik, D. Stuctural Bonding Tapes and Articles Containing the Same. Patent Application WO079337, 10 November 2002.

2. Bernardus, J.; Sikkel, F.; Brandys, A.; Chen, P. Adhesive Tape for Structural Bonding. Patent Application WO 2005073330, 11 August 2005.

3. Sohaib, E.; Cura, E. Structural Adhesive Film. Patent Application WO 2005073330, 23 August 2012.

4. Cura, E.; Elgimiabi, S.; Luebbe, S.; Shinozaki, K.; Ueda, S. Multilayer Structural Adhesive Film. Patent Application US10632707, 28 April 2020.

5. Higgins, A. Adhesive bonding of aircraft structures. Int. J. Adhes. Adhes. 2000, 20, 367-376. [CrossRef]

6. LaPlante, G.; Lee-Sullivan, P. Moisture Effects on FM300 Structural Film Adhesive: Stress Relaxation, Fracture Toughness, and Dynamic Mechanical Analysis. J. Appl. Polym. Sci. 2005, 95, 1285-1294. [CrossRef]

7. Pal, R.; Sudhi, S.; Raghavan, R. Fabrication and evaluation of structural film adhesive using oxazolidinone modified novolac epoxy resin. J. Appl. Polym. Sci. 2019, 136, 47520. [CrossRef]

8. Dementeva, L.; Kutsevich, K.; Lukina, N.; Rubtsova, E.; Petrova, A. Properties of an Epoxy Structural Film Adhesive Modified by Polysulfones. Polym. Sci. Part D 2017, 10, 143-149. [CrossRef]

9. Kowalczyk, A.; Kowalczyk, K.; Czech, Z. Synthesis and properties of solid structural adhesives modified in-situ using 1D and 2D-type microfillers. Int. J. Adhes. Adhes. 2012, 32, 76-81. [CrossRef]

10. Kowalczyk, A.; Kowalczyk, K.; Weisbrodt, M. Influence of phosphorus-based methacrylate monomer on features of thermally curable self-adhesive structural tapes. Int. J. Adhes. Adhes. 2018, 85, 286-292. [CrossRef]

11. Kowalczyk, A.; Kowalczyk, K.; Gziut, K.; Nowakowski, D.; Sałaciński, M. Influence of a wollastonite microfiller and a halloysite nanofiller on properites of thermally curable pressure-sensitive structural adhesives. Int. J. Adhes. Adhes. 2019, 95, 102397. [CrossRef] 
12. Kowalczyk, A.; Kowalczyk, K.; Gziut, K. Synthesis of Monoacryloxypropyl-POSS-based Hybrid Epoxyacrylate Copolymers and Their Application in Thermally Curable Structural Self-Adhesive Tapes. Polymers 2019, 11, 2058. [CrossRef]

13. Fouassier, J.; Lalevée, J. Photoinitiators for Polymer Synthesis. Scope, Reactivity and Efficiency; Wiley-VCH Verlag GmbH\&Co. KGaA: Weinheim, Germany, 2012.

14. Boodhoo, K.; Dunk, W.; Jassim, M.; Jachuck, R. Thin Film Solvent-Free Photopolymerization of n-Butyl Acrylate. I. Static Film Studies. J. Appl. Polym. Sci. 2004, 91, 2079-2095. [CrossRef]

15. Garra, P.; Dietlin, C.; Morlet-Savary, F.; Dumur, F.; Gigmes, D.; Fouassiera, J.; Lalevée, J. Photopolymerization processes of thick films and in shadow areas: A review for the access to composites. Polym. Chem. 2017, 8 , 7088-7101. [CrossRef]

16. Ming, L.; Schlüter, D.; Sakamoto, J. Solid-State Photopolymerization of a Shape-Persistent Macrocycle with Two 1,8-Diazaanthracene Units in a Single Crystal. J. Am. Chem. Soc. 2012, 134, 11721-11725. [CrossRef]

17. Eckhardt, H.; Prusik, T.; Chance, R. Solid-State Photopolymerization of Diacetylenes. In Polydiacetylenes; Bloor, D., Chance, R.R., Eds.; Springer: Dordrecht, The Netherlands, 1985; pp. 25-39. [CrossRef]

18. Wang, J.; Jian, Y.; Nie, J.; He, Y. Solid photopolymerization and polymer properties of octadecyl vinyl ether. J. Photochem. Photobiol. A Chem. 2013, 271, 105-110. [CrossRef]

19. Bagheri, A.; Jin, J. Photopolymerization in 3D Printing. ACS Appl. Polym. Mater. 2019, 1, 593-611. [CrossRef]

20. Liu, X.; Sharapov, V.; Zhang, Z.; Wiser, F.; Awaisa, M.; Yu, L. Photoinduced cationic polycondensation in solid state towards ultralow band gap conjugated polymers. J. Mater. Chem. C 2020, 8, 7026-7033. [CrossRef]

21. Andrzejewska, E. Photoinitiated polymerization in ionic liquids and its application. Polym. Int. 2017, 66, 366-381. [CrossRef]

22. Marcinkowska, A.; Zgrzeba, A.; Lota, G.; Kopczyński, K.; Andrzejewska, E. Ionogels by thiol-ene photopolymerization in ionic liquids: Formation, morphology and properties. Polymer 2019, 160, $272-281$. [CrossRef]

23. Simms, H.; Brotherton, C.; Good, B.; Davis, R.; Ansethaband, K.; Bowman, C. In situ fabrication of macroporous polymer networks within microfluidic devices by living radical photopolymerization and leaching. Lab Chip 2005, 5, 151-157. [CrossRef]

24. Choi, Ch.; Jung, J.; Hwang, T.; Lee, C. In Situ Microfluidic Synthesis of Monodisperse PEG Microspheres. Macromol. Res. 2009, 17, 163-167. [CrossRef]

25. Khudyakov, I.; Arsu, N.; Jockusch, S.; Turro, N. Magnetic and spin effects in the photoinitiation of polymerization. Des. Monomers Polym. 2003, 6, 91-101. [CrossRef]

26. Jang, S.; Baek, S.; Kim, J.; Hwang, S. Preparation and adhesion performance of transparent pressure-sensitive adhesives for touch screen panel. J. Adhes. Sci. Technol. 2014, 28, 1990-2000. [CrossRef]

27. Beak, S.; Hwang, S. Eco-friendly UV-curable pressure sensitive adhesives containing acryloyl derivatives of monosaccharides and their adhesive performances. Int. J. Adhes. Adhes. 2016, 70, 110-113. [CrossRef]

28. Beak, S.; Hwang, S. Preparation and adhesion performance of transparent acrylic pressure-sensitive adhesives containing menthyl acrylate. Polym. Bull. 2016, 73, 687-701. [CrossRef]

29. Baek, S.; Jang, S.; Hwang, S. Preparation and adhesion performance of transparent acrylic pressure sensitive adhesives: Effects of substituent structure of acrylate monomer. Int. J. Adhes. Adhes. 2016, 64, 72-77. [CrossRef]

30. Baek, S.; Jang, S.; Hwang, S. Sustainable isosorbide-based transparent pressure-sensitive adhesives for optically clear adhesive and their adhesion performance. Polym. Int. 2017, 66, 1834-1840. [CrossRef]

31. Baek, S.; Jang, S.; Hwang, S. Construction and adhesion performance of biomass tetrahydro-geraniol-based sustainable/transparent pressure sensitive adhesives. J. Ind. Eng. Chem. 2017, 53, 429-434. [CrossRef]

32. Kim, J.; Shim, G.; Baek, D.; Back, J.; Jang, S.; Kim, H.; Choi, J.; Yeom, J. UV/UV step-curing of optically clear acrylate adhesives for mobile devices. Express Polym. Lett. 2019, 13, 794-805. [CrossRef]

33. Zhang, Y.; He, Y.; Zhang, X.; Nie, J. $\alpha$-hydroxyalkyl ketones deriatives used as photoinitiators for photografting field. J. Photochem. Photobiol. A Chem. 2017, 349, 193-196. [CrossRef]

34. Ikemura, K.; Ichizawa, K.; Yoshida, M.; Ito, S.; Endo, T. UV-VIS spectra and photoinitiation behavior of acylphospine oxide and bisacylphosphine oxide derivatives in unfilled, light-cured resins. Dent. Mat. J. 2008, 27, 765-774. [CrossRef] 
35. Lee, K.; Ware, T.; Tondiglia, V.; McBride, M.; Zhang, X.; Bowman, C.; White, T. Initiatorless Photopolymerization of Liquid Crystal Monomers. ASC Appl. Mater. Interfaces 2016, 8, 28040-28046. [CrossRef]

36. Graff, B.; Klee, J.; Fik, C.; Maier, M.; Fouassier, J.; Lelevée, J. Development of Novel Photoinitiators as Substitutes of Camphorquinones for the LED Induced Polymerization of Methacrylates: A Bis-Silyl Ketone. Macromol. Rapid Commun. 2016, 38, 1600470. [CrossRef]

37. Dietlin, C.; Trinh, T.; Schweizer, S.; Graff, B.; Morlet-Savary, F.; Noirot, P.; Lelevée, J. New Phosphine Oxides as High Performance Near-UV Type I Photoinitiators of Radical Polymerization. Molecules 2020, 25, 1671. [CrossRef] [PubMed]

38. Doran, S.; Taskin, O.; Tasdelen, M.; Yaci, Y. Controlled photopolymerization and novel architectures. In Dyes and Chromophores in Polymer Science; Fouassier, J., Lelevée, J., Eds.; John Wiley \& Sons: London, UK, 2015; pp. 81-100.

39. Wang, Y.; Liu, F.; Xue, X. Morphology and properties of UV-curing epoxy acrylate coatings modified with methacryl-POSS. Prog. Org. Coat. 2015, 78, 404-410. [CrossRef]

40. Glöckner, P. Radiation Curing. Coatings and Proniting Inks; Vincentz Network: Hannover, Germany, 2008.

41. Baxter, J.; Davidson, R. Acylphosphine oxides as photoinitiators for acrylate and unsaturated poliester resins. Eur. Polym. J. 1988, 24, 419-424. [CrossRef]

42. Tehfe, M.; Louradour, F.; Lalevée, J.; Fouassier, J. Photopolymerization Reactions: On the Way to a Green and Sustainable Chemistry. Appl. Sci. 2013, 3, 490-514. [CrossRef]

43. Khan, I.; Poh, B. Effect of molecular weight and testing rate on adhesion property of pressure-sensitive adhesives prepared from epoxidized natural rubber. Mater. Des. 2011, 32, 2513-2519. [CrossRef]

44. Zhao, J.; Yu, P.; Dong, S. The Influence of Crosslink Density on the Failure Behavior in Amorphous Polymers by Molecular Dynamics Simulations. Materials 2016, 9, 234. [CrossRef]

45. Ricciotti, L.; Roviello, G.; Tarallo, O.; Borbone, F.; Ferone, C.; Colangelo, F.; Catauro, M.; Cioffi, R. Synthesis and Characterizations of Melamine-Based Epoxy Resins. Int. J. Mol. Sci. 2013, 14, 18200-18214. [CrossRef]

(C) 2020 by the authors. Licensee MDPI, Basel, Switzerland. This article is an open access article distributed under the terms and conditions of the Creative Commons Attribution (CC BY) license (http://creativecommons.org/licenses/by/4.0/). 